\title{
POLYNOMIAL INTERPOLATION OF THE OBTAINED DEPTH OF NITROGEN DIFFUSION ON THE SURFACE OF THE PLASMA NITRIDED X5CrNi18-10 AUSTENITIC STEEL
}

\author{
Marzena Ogórek ${ }^{1}$, Grzegorz Biernat ${ }^{2}$, Tadeusz Frączek ${ }^{1}$, Marcin Knapiński ${ }^{1}$ \\ ${ }^{I}$ Faculty of Production Engineering and Materials Technology \\ Czestochowa University of Technology, \\ Czestochowa, Poland \\ ${ }^{2}$ Department of Mathematics, Czestochowa University of Technology, Częstochowa, Poland
}

\begin{abstract}
In the paper the polynomial tensor interpolation of the obtained results of the nitrogen diffusion depth on the surface of austenitic steel type 304 is presented.
\end{abstract}

Keywords: polynomial tensor interpolation, depth of nitrogen diffusion

\section{Introduction}

This work presents the polynomial tensor interpolation of the obtained results of the nitrogen diffusion depth on the surface of austenitic steel type 304 according to AISI (X5CrNi18-10 according to PN-EN 10088-1:1998), which was subjected to a plasma nitriding process according to the principles of mathematical planning of the research in a temperature range of $\mathrm{T}=538 \div 673 \mathrm{~K}\left(325 \div 400^{\circ} \mathrm{C}\right)$ and time of $7.2 \div 14.4 \mathrm{ks}$ (from 2 to $4 \mathrm{~h}$ ) for two different variants of locating the specimens in a plasma chamber. In the first variant, the elements subjected to nitriding were located on the cathode; in the second variant, the nitrided elements located on the cathode were additionally covered with an active screen in order to intensify the impact of plasma discharged during the nitriding process.

In order to achieve the assumed goals, the analysis of the elements distribution profile was carried out in the surface layer using a glow discharge optical emission spectrometer HORIBA JobinYvon GD-Profiler HR (RF GDOES: GlowDischarge Optical EmissionSpectroscopy) with a Grimm-type glow discharge lamp. Its cathode diameter was $4 \mathrm{~mm}$. On the basis of the analysis of the chemical composition profile, the depth of nitrogen diffusion was determined depending on the assumed parameters of the nitriding process shown in the scheme of the mathematical planning of analyses. It was stated that the use of the active screen causes intensification of the plasma nitriding process. This results in a $2 \div 6$ - time increase of the depth of nitrogen diffusion into a nitrided surface of X5CrNi18-10 austenitic steel 
when the active screen is used in comparison to the variant of cathode nitriding. More than that, the analysis of the nitrogen content in the obtained surface layers showed that the temperature increase of the nitriding process and prolongation of its duration caused the increase of nitrogen concentration in the subsurface zone and the increase of depth of its diffusion into the nitrided surface.

The obtained values of nitrogene concentration in the nitrided surface layers were determined for 12 data points of the assumed plan. In order to determine nitrogen concentration in the rest of the range of the assumed research zone, a polynomial interpolation of the results of nitrogen diffusion in the obtained surface layers was carried out. Interpolation of the results of the depth of diffusion enables description of this feature in a form of a polynomial function and obtain the value of this function in unmeasured points inside the research zone. The polynomial interpolation is determined unequivocally.

\section{Material and the scope of the research}

The plasma nitriding process was carried out on one of the most frequently used austenitic steels from the group of chromium-nickel steels, mainly type 304 according to AISI (X5CrNi18-10 according to PN-EN 10088-1:1998). Its chemical composition is presented in Table 1.

Table 1

Chemical composition of 304 steel

\begin{tabular}{|c|c|c|c|c|c|c|c|c|c|c|c|c|}
\hline \multicolumn{2}{|c|}{ Element } & C & $\mathrm{Cr}$ & $\mathbf{N i}$ & Mo & Mn & $\mathbf{N}$ & $\mathrm{Si}$ & $\mathbf{P}$ & s & $\mathrm{Cu}$ & $\mathrm{Fe}$ \\
\hline \multirow{2}{*}{1} & Min & - & 17,00 & 8,0 & - & - & - & - & - & 0,015 & - & \multirow{3}{*}{ rest } \\
\hline & $\max$ & 0,07 & 19,00 & 10,50 & - & 2,0 & 0,11 & 1,0 & 0,045 & 0,03 & - & \\
\hline 2 & $=$ & 0,03 & 18,3 & 10,00 & - & 2,0 & 0,17 & - & - & - & - & \\
\hline
\end{tabular}

Parameters of low-temperature and short-time plasma nitriding were assumed on the basis of the initial analyses carried out for austenitic steels [1,2].

The processes of plasma nitriding were carried out according to the principles of mathematical planning of research (Fig. 1) using the equipment for plasma treatment with a cooling anode JON-600 type. The following parameters of nitriding in hydrogen-nitrogen plasma were applied: process pressure $\mathrm{p}=150 \mathrm{~Pa}$, range of temperatures $\mathrm{T}=538 \div 673 \mathrm{~K}\left(325 \div 400^{\circ} \mathrm{C}\right)$, time of the process from 7.2 to $14.4 \mathrm{ks}$ $(2 \div 4 \mathrm{~h})$.

Two variants of locating the specimens in a plasma chamber were applied:

- the specimens were located directly on the cathode,

- the specimens located on the cathode were additionally covered by a screen made of a perforated austenitic steel sheet. 


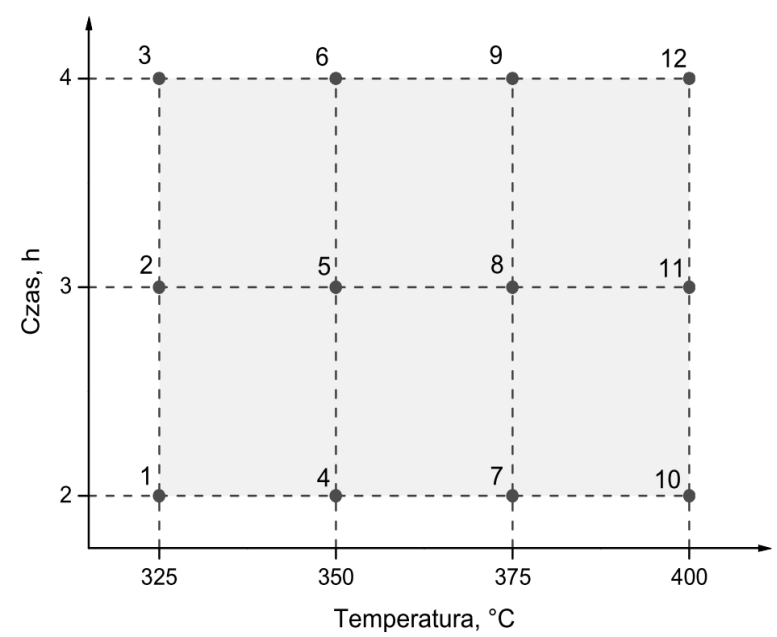

Fig. 1. Mathematical scheme of the selected research plan

In the first case the surface of the specimens was bombed with ions which energy follows from the value of cathode potential drop. However, in the second case strong potential peaks in the area of the surface layer appear. They must react with nitrogen ions present in this zone. The time of potential peaks duration favours that ions obtain high speeds which correspond to kinetic energy of dozens or even hundreds of electron volts. These ions are hammered into the material and make a strongly nonequilibrium nitrogen saturated surface area. It favours diffusion of nitrogen inside the material. Regarding high gradients of concentration the diffusion does not have to, at least in its initial stage, take place on the grain borders, which fosters formation of highly homogeneous nitrided layers [1].

The analyses of elements distribution profile in the surface layer were carried out on a glow discharge optical emission electroscope HORIBA JobinYvon GD-Profiler HR (RF GDOES: Glow Discharge Optical Emission Spectroscopy) with a Grimm-type glow discharge lamp with the cathode diameter of $4 \mathrm{~mm}$. The GDOES method was introduced in 1968 by W. Grimm. A measuring chamber suggested by Grimm has been used since then.

\section{Polynomial interpolation of abrasive wear resistance}

Polynomial interpolation was determined using $\mathrm{C}++$ Builder 5.0 software described in work [3]. The interpolation of the obtained results of diffusion depth is given by a polynomial with two variables, temperature $T$ and time $t[3,4]$. In the case of plasma nitriding with the use of the "activescreen method", a possible to obtain depth of diffusion was described by the dependence (1); however, for the cathode nitriding a possible to obtain depth of diffusion was described by the dependence (2): 


$$
\begin{aligned}
& g_{E}(T, t)=\frac{1}{\operatorname{det}\left(\left[T_{j k}\right]_{1 \leq j, k \leq 4} \otimes\left[t_{p q}\right]_{1 \leq p, q \leq 3}\right)} \sum_{\substack{1 \leq j \leq 4 \\
1 \leq p \leq 3}}\left(\operatorname{det} A_{j p}\right) T^{j-1} t^{p-1} \\
& g_{K}(T, t)=\frac{1}{\operatorname{det}\left(\left[T_{j k}\right]_{1 \leq j, k \leq 4} \otimes\left[t_{p q}\right]_{1 \leq p, q \leq 3}\right)} \sum_{\substack{1 \leq j \leq 4 \\
1 \leq p \leq 3}}\left(\operatorname{det} B_{j p}\right) T^{j-1} t^{p-1}
\end{aligned}
$$

where:

$$
\left[T_{j k}\right]=\left[\begin{array}{cccc}
1 & T_{1} & T_{1}^{2} & T_{1}^{3} \\
1 & T_{2} & T_{2}^{2} & T_{2}^{3} \\
1 & T_{3} & T_{3}^{2} & T_{3}^{3} \\
1 & T_{4} & T_{4}^{2} & T_{4}^{3}
\end{array}\right]
$$

$T_{1}, T_{2}, T_{3}, T_{4}$ - temperatures of the nitriding process, and

$$
\left[t_{p q}\right]=\left[\begin{array}{lll}
1 & t_{1} & t_{1}^{2} \\
1 & t_{2} & t_{2}^{2} \\
1 & t_{3} & t_{3}^{2}
\end{array}\right]
$$

$t_{1}, t_{2}, t_{3}$ - times of exposition of a specimen in a given temperature $T_{1}, T_{2}, T_{3}, T_{4}$.

The matrix $A_{j p}$ means algebraic substitution of jp-row of the matrix $\left[T_{j k}\right] \otimes\left[t_{p q}\right]$ by a column of results:

$\left[\left(\mathrm{g}_{\mathrm{E}}\right)_{\mathrm{jp}}\right]=[0.5 ; 0.9 ; 1.6 ; 1.3 ; 2.2 ; 2.8 ; 2.8 ; 4.2 ; 4.6 ; 5.3 ; 6.1 ; 7.3]^{\text {transposition }}$

$\left[\left(\mathrm{g}_{\mathrm{K}}\right)_{\mathrm{jp}}\right]=[0.3 ; 0.4 ; 0.5 ; 0.4 ; 0.6 ; 0.8 ; 0.5 ; 0.7 ; 1.9 ; 1.1 ; 1.6 ; 2.5]^{\text {transposition }}$.

To determine the depth of diffusion it was assumed that: $\mathrm{T}_{1}=325^{\circ} \mathrm{C}$, $\mathrm{T}_{2}=350^{\circ} \mathrm{C}, \mathrm{T}_{3}=375^{\circ} \mathrm{C}, \mathrm{T}_{4}=400^{\circ} \mathrm{C}$ and $\mathrm{t}_{1}=2 \mathrm{~h}, \mathrm{t}_{2}=3 \mathrm{~h}, \mathrm{t}_{4}=4 \mathrm{~h}$.

\section{Research results and discussion}

On the basis of the analysis of the chemical composition profile, the depth of nitrogen diffusion was determined regarding the parameters assumed in the scheme of the research planning. The analysis of the obtained research results (Tables 2, 3) showed that during cathode nitriding of X $5 \mathrm{CrNi} 18-10$ austenitic steel there nitrided layers of the depth in the range of $0.3 \div 2.5 \mu \mathrm{m}$ were obtained. However, the use of the "activescreen" method caused the obtainment of the layers with the depth in the range of $0.5 \div 7.3 \mu \mathrm{m}$. The obtained results allow stating that the use of the "activescreen" method caused almost $2 \div 6$ - time increase of the depth of diffusion of the obtained nitrided layers in relation to the cathode process carried out in the same conditions. 
Table 2

Depth of nitrogen diffusion for the plasma nitrided specimens using the "activescreen" method

\begin{tabular}{|c|c|c|c|c|}
\hline \multirow{2}{*}{ Time [h] } & \multicolumn{4}{|c|}{ Temperature $\left[{ }^{\circ} \mathrm{C}\right]$} \\
\cline { 2 - 5 } & 325 & 350 & 375 & 400 \\
\cline { 2 - 5 } & \multicolumn{4}{|c|}{ Depth of nitrogen diffusion $[\mu \mathrm{m}]$} \\
\hline 2 & 0.5 & 1.3 & 2.8 & 5.3 \\
\hline 3 & 0.9 & 2.2 & 4.2 & 6.1 \\
\hline 4 & 1.6 & 2.8 & 4.6 & 7.3 \\
\hline
\end{tabular}

Table 3

Depth of nitrogen diffusion for the cathode plasma nitrided specimens

\begin{tabular}{|c|c|c|c|c|}
\hline \multirow{2}{*}{ Time [h] } & \multicolumn{4}{|c|}{ Temperature [ $\left.{ }^{\circ} \mathrm{C}\right]$} \\
\cline { 2 - 5 } & 325 & 350 & 375 & 400 \\
\cline { 2 - 5 } & & \multicolumn{4}{|c|}{ Depth of nitrogen diffusion $[\mu \mathrm{m}]$} \\
\hline 2 & 0.3 & 0.4 & 0.5 & 1.1 \\
\hline 3 & 0.4 & 0.6 & 0.7 & 1.6 \\
\hline 4 & 0.5 & 0.8 & 1.9 & 2.5 \\
\hline
\end{tabular}

The depth of nitrogen diffusion after the plasma nitriding process in the function of time and temperature in the area of the research was described by interpolated surface (Figs. 2,3) and by a polynomial (1), (2). The set of data points is presented in Tables 4 and 5.

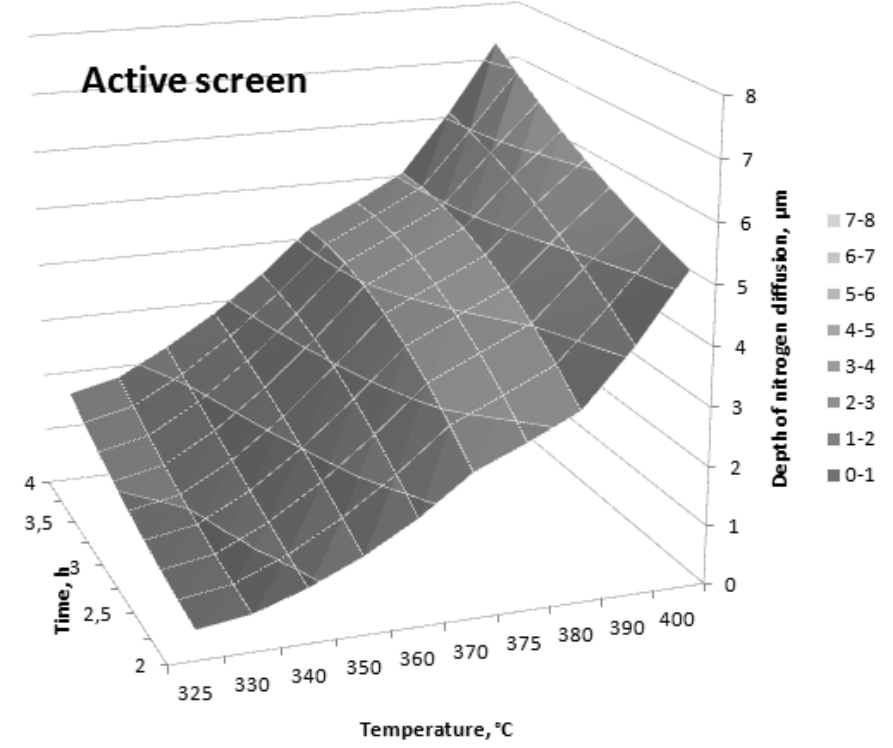

Fig. 2. Polynomial interpolation of the obtained results of depth of nitrogen diffusion as a result of plasma nitriding using the "activescreen" method 


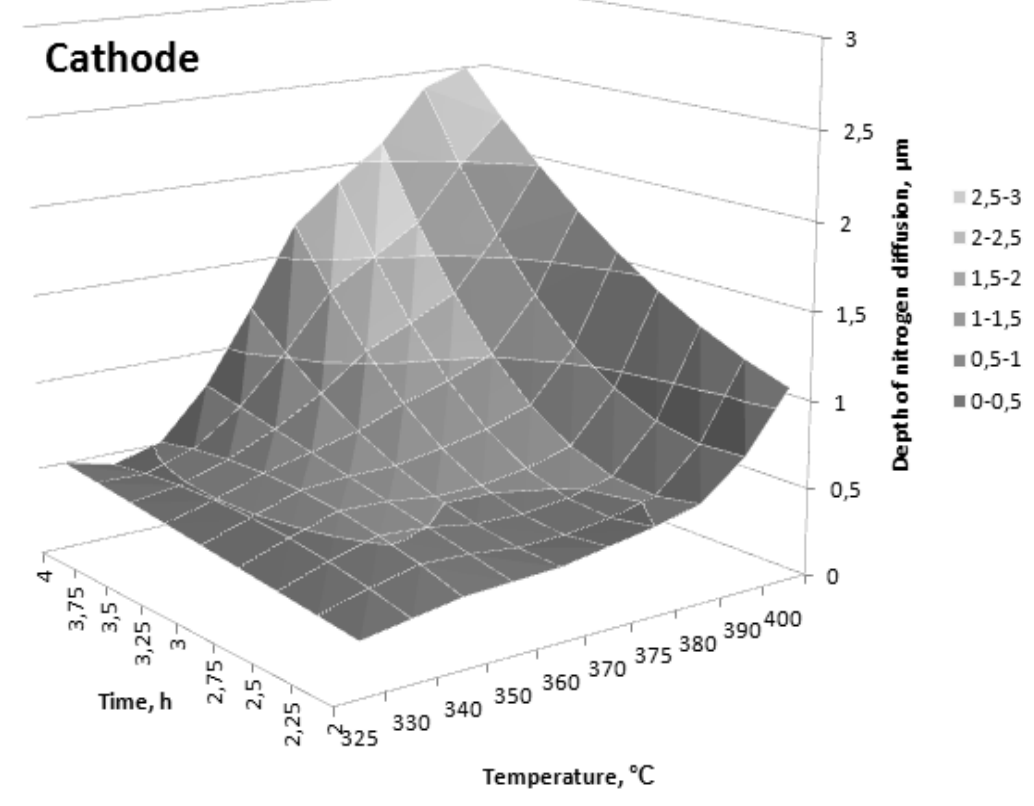

Fig. 3. Polynomial interpolation of the obtained results of depth of nitrogen diffusion as a result of cathode plasma nitriding

Table 4

Depth of nitrogen diffusion obtained as a result of polynomial interpolation after plasma nitriding using the "activescreen" method

\begin{tabular}{|c|c|c|c|c|c|c|c|c|c|c|}
\hline \multirow{3}{*}{$\underset{\Xi}{\Xi}$} & \multicolumn{10}{|c|}{ Temperature $\left[{ }^{\circ} \mathrm{C}\right]$} \\
\hline & 325 & 330 & 340 & 350 & 360 & 370 & 375 & 380 & 390 & 400 \\
\hline & \multicolumn{10}{|c|}{ Depth of nitrogen diffusion between the data points $[\mu \mathrm{m}]$} \\
\hline 2 & 0.50 & 0.62 & 0.91 & 1.30 & 1.80 & 2.43 & 2.80 & 3.21 & 4.16 & 5.30 \\
\hline 2.25 & 0.57 & 0.70 & 1.07 & 1.55 & 2.15 & 2.86 & 3.24 & 3.65 & 4.52 & 5.46 \\
\hline 2.5 & 0.66 & 0.81 & 1.22 & 1.79 & 2.47 & 3.23 & 3.62 & 4.03 & 4.85 & 5.65 \\
\hline 2.75 & 0.77 & 0.93 & 1.38 & 2.00 & 2.74 & 3.53 & 3.94 & 4.35 & 5.14 & 5.86 \\
\hline 3 & 0.90 & 1.07 & 1.55 & 2.20 & 2.96 & 3.78 & 4.20 & 4.61 & 5.40 & 6.10 \\
\hline 3.25 & 1.05 & 1.22 & 1.72 & 2.38 & 3.14 & 3.97 & 4.39 & 4.81 & 5.63 & 6.36 \\
\hline 3.5 & 1.21 & 1.40 & 1.90 & 2.54 & 3.28 & 4.10 & 4.52 & 4.96 & 5.82 & 6.65 \\
\hline 3.75 & 1.40 & 1.59 & 2.08 & 2.68 & 3.38 & 4.17 & 4.59 & 5.04 & 5.97 & 6.96 \\
\hline 4 & 1.60 & 1.81 & 2.26 & 2.80 & 3.43 & 4.18 & 4.60 & 5.06 & 6.09 & 7.30 \\
\hline
\end{tabular}


Table 5

Depth of nitrogen diffusion obtained as a result of polynomial interpolation after cathode plasma nitriding

\begin{tabular}{|c|c|c|c|c|c|c|c|c|c|c|c|}
\hline \multirow{2}{*}{$\begin{array}{c}\Xi \\
\Xi\end{array}$} & \multicolumn{10}{|c|}{ Temperature $\left[{ }^{\circ} \mathrm{C}\right]$} \\
\cline { 2 - 12 } & 325 & 330 & 340 & 350 & 360 & 370 & 375 & 380 & 390 & 400 \\
\cline { 2 - 12 }$y$ & \multicolumn{8}{|c|}{ Depth of nitrogen diffusion between the data points $[\mu \mathrm{m}]$} \\
\hline 2 & 0.30 & 0.34 & 0.39 & 0.40 & 0.41 & 0.46 & 0.50 & 0.56 & 0.77 & 1.10 \\
\hline 2.25 & 0.33 & 0.40 & 0.46 & 0.45 & 0.42 & 0.42 & 0.46 & 0.52 & 0.75 & 1.19 \\
\hline 2.5 & 0.35 & 0.44 & 0.52 & 0.50 & 0.45 & 0.44 & 0.48 & 0.54 & 0.80 & 1.30 \\
\hline 2.75 & 0.37 & 0.47 & 0.56 & 0.55 & 0.51 & 0.52 & 0.56 & 0.63 & 0.91 & 1.44 \\
\hline 3 & 0.40 & 0.49 & 0.58 & 0.60 & 0.60 & 0.64 & 0.70 & 0.79 & 1.09 & 1.60 \\
\hline 3.25 & 0.42 & 0.50 & 0.59 & 0.65 & 0.72 & 0.82 & 0.91 & 1.01 & 1.32 & 1.79 \\
\hline 3.5 & 0.45 & 0.49 & 0.58 & 0.70 & 0.86 & 1.06 & 1.18 & 1.31 & 1.62 & 2.00 \\
\hline 3.75 & 0.48 & 0.47 & 0.55 & 0.75 & 1.02 & 1.34 & 1.51 & 1.67 & 1.98 & 2.24 \\
\hline 4 & 0.50 & 0.43 & 0.51 & 0.80 & 1.22 & 1.68 & 1.90 & 2.10 & 2.40 & 2.50 \\
\hline
\end{tabular}

\section{Conclusions}

Depth of nitrogen diffusion is the only property of the nitrided layer which depends on two parameters of the nitriding process: time and temperature. In order to determine the depth of nitride diffusion in the analyzed austenitic steel, polynomial interpolation of the obtained results of nitrogen diffusion in data points was used.

The assumed method of approximation between the data points was carried out in polynomials of the second degree. A question arises whether the change of class of the function has an influence on the improvement of the results of approximation. Exponential functions and hyperbolic functions will be described in further research. Functions of these classes seem to be good enough to describe the course of the interpolating surface at a "low" side of the interpolated area, for long times of steel nitriding.

\section{References}

[1] Frączek T., Niekonwencjonalne niskotemperaturowe azotowanie jarzeniowe materiałów metalicznych, Wyd. WIPMiFS, Częstochowa 2011.

[2] Ogórek M., Efektywność azotowania jonowego stali austenitycznej X5CrNi18-10 metodą „activescreen”, Praca doktorska, Częstochowa 2014.

[3] Biernat G., Ciekot A., The polynomial tensor interpolation. Arithmetical case, Scientific Research of the Institute of Mathematics and Computer Science 2009, 1(8), 7-11.

[4] Biernat G., Ciekot A., The polynomial interpolation for technical experiments, Scientific Research of the Institute of Mathematics and Computer Science 2007, 1(6), 19-22.

[5] Frączek T., Olejnik M., Knapiński M., Biernat G., Tensor interpolation of tribological wear in ionnitriding of 316L steel, Solid State Phenomena 2010, 165, 43-49. 